\title{
Can Recreation Exist in Healthcare? Recreational Therapy and Its Professionalization \\ Naomi Yoshioka
}

Department of Physical Recreation, Tokai University, 4-1-1 Kitakaname, Hiratsuka, Kanagawa 259-1292, Japan

Considering the low recognition toward recreational therapy (or therapeutic recreation) in healthcare and rehabilitation, this paper discusses the long-time controversy over TR/RT professional philosophy and an international perspective regarding its professionalization including future direction of Japanese recreation services.

A few years ago, a colleague shared with me an article from The Economist, entitled "The future of jobs: the onrushing wave," showing that the occupation of recreational therapist has the lowest probability of replacement by automation [1]. The article further emphasized the critical need for specialists engaged in emotional and relational work and that working in these fields is inherently noble [1]. As a certified therapeutic recreation specialist (CTRS), this article helped me appreciate anew the occupational worth of my fellow CTRSs and recreational professionals. At the same time, however, I wonder how many people recognize my profession's very existence.

Recreation therapy (RT; also known as therapeutic recreation [TR]) is "a systematic process that utilizes recreation and other activitybased intervention to address the assessed needs of individuals with illness and/or disabling conditions, as a means to psychological and physical health, recovery and well-being [2]". These professionals provide a variety of activities, including arts and crafts, sports and physical activity, games, dance and movement, drama, music, and activities in community settings [3]. According to the National Council for Therapeutic Recreation Certification (NCTRC), 11,554 CTRSs are primarily serving in hospitals, skilled nursing facilities, and other facilities [4]. Historically, RT/TR was developed and organized in the United States, and is mostly known in North America. Despite its development as a profession in both community and healthcare settings for over a half-century, it seems that the field has not received proper recognition. Data from the U.S. Bureau of Labor Statistics [5] revealed 18,600 RT jobs compared to 114,600 jobs in occupational therapy (OT) and 214,900 in physical therapy (PT). Statistics also indicate that median pay in RT is $\$ 44,000$ per year compared to $\$ 78,810$ in OT and $\$ 82,390$ in PT. In addition, in their review of a previous study, Harkins and Bedini [6] indicated the less frequent inclusion of RT in healthcare textbooks compared to PT and OT, and the presence of occupational prejudice of PTs and OTs toward RTs. Furthermore, based on a web-based survey of administrative positions in healthcare facilities, they learned that RT was not sufficiently recognized by healthcare administrators, and explained that administrators do not have accurate knowledge of RT, including its level of education and training, and that RT was the least utilized treatment. Finally, Harkins and Bedini found that administrators were more likely to believe that RT services can be handled by other healthcare professions.

What would account for this situation? One answer might emerge from the long-time controversy over TR/RT professional philosophy. As Dieser [7] stated, "Nothing can be further from the truth, as the American TR profession has a history of being a turbulent and divided profession over the philosophical orientation of services (treatment/ therapy versus the provision of leisure) and continues to be a profession in turmoil." Instead of concretizing the professional philosophy, recent movements toward locating its position within a medical model seem

\section{Publication History:}

Received: January 18, 2016

Accepted: February 06, 2016

Published: February 09, 2016

\section{Keywords:}

Recreational therapy, Professionalization, Healthcare, Certified therapeutic recreation specialist

to have repeatedly generated discussion. Above all, to develop TR/ $\mathrm{RT}$ in countries around the world, engaging in a discussion about the American-based TR/RT model has been suggested. World Leisure Journal, for example, edited a special issue on TR/RT, bringing an international perspective regarding its professionalization.

Papers in this special issue intimated that the American-based TR/ RT model, which focuses more on treatment/therapy, might not be the only way to think about occupational prestige. For instance, to explain the failure of TR/RT in providing functional outcomes in the field, Mobily [8] deconstructed the medical model approach to TR/RT, arguing that adopting an American-based TR/RT would be a mistake for the global community, and criticized the tendency to leaning on the words "therapy" and "therapeutic" with less perspective on leisure experiences. Mobily questioned as follows:

Is TR/RT asking the wrong questions because of the hegemony of the medical model? How much has TR/RT been party to harm done by promoting paternalistic relationships with disabled persons? How much does the myopic focus on functional outcomes distract from leisure-driven outcomes, such as enjoyment, social interaction, skill development, attitude change and friendship formation?

Mobily's suggestion for finding an alternative global model of recreation appears necessary for different countries. Hebblethwaite [9], as a representative of the Canadian Therapeutic Recreation Association, the first international organization to enter a professional partnership with NCTRC in 2009, emphasized that TR/RT in Canada should develop a certified system compatible with their bilingualism and diverse educational system. Young [10] also addressed the need for partnership between recreation professionals and OTs as well as biokinetics to improve the health and well-being of people with disabilities in South Africa. As Mobily [11] further suggested in his 8 Principles for globalization in TR/RT, each country should develop its own culturally appropriate TR/RT services.

*Corresponding Author: Dr. Naomi Yoshioka, Department of Physical Recreation, Tokai University, 4-1-1 Kitakaname, Hiratsuka, Kanagawa 259-1292, Japan; E-mail: naomiy@keyaki.cc.u-tokai.ac.jp

Citation: Yoshioka (2016) Can recreation Exist in Healthcare? Recreationa Therapy and Its Professionalization. Int J Phys Ther Rehab 2: 110. doi: http:// dx.doi.org/10.15344/2455-7498/2016/110

Copyright: () 2016 Yoshioka. This is an open-access article distributed under the terms of the Creative Commons Attribution License, which permits unrestricted use, distribution, and reproduction in any medium, provided the original author and source are credited. 
As for TR/RT in my own country, Japan, it now seems time to reconstruct its position. In particular, Japan has the highest percentage of aging persons in the world; therefore, the availability of leisure time and later-life activities is an important change. Considering not just health, but quality of life and meaning in life, TR/RT should be a valued profession. However, similar to American TR/RT, Japanese society has not fully recognized the profession known as fukushi recreation (fukushi meaning "welfare" in Japanese). Furthermore, Murray [12] mentioned that due to Japanese TR/RT's original development within the concept of welfare and the firmly rooted Japanese traditional work ethic, the profession's unique aspects of leisure (i.e., enjoyment) have been difficult to characterize.

Despite having a qualification system for certified fukushi recreation workers, there are few opportunities for employment in healthcare settings in Japan. Also, topics related to recreation were eliminated from the educational curriculum for care workers, the primary healthcare profession responsible for providing ADL as well as recreational activities in hospitals and long-term care facilities. This state of affairs has led to a decrease in the number of professionals who possess knowledge and skills in recreation. At the same time, reform of Japan's long-term care insurance system has promoted implementation of a community-based integrated care system in which clients are encouraged to live in their own community as long as possible [13]. With this reform, healthcare professionals, such as OTs and PTs, have shifted their services toward social capital and communities, with a consequent absorption of TR/RT activities into OT or PT services. In their quantitative study, Luchauer and Shurtleff [14] suggested that exercise and active recreation are useful interventions for providing OT clients with a sense of purpose and well-being both after discharge and for reintegration into the community. In fact, TR/RT has presented this recommendation as evidence of the effectiveness of TR/RT for supporting clients' quality of life, as stated by Richter and Kaschelk [15]

The therapeutic recreation specialist can help people find and insert meaning into the substance of their lives. Why would someone want to learn to walk if they have nowhere to walk to? Why does someone want to get dressed if there is nothing to get dressed up for? The therapeutic recreation specialist may be the only person, with the possible exception of the chaplain, who is addressing these vital questions.

TR/RT must preserve the unique characteristics of the profession by providing clear evidence presented in a way that other healthcare professionals, especially administrators, can accept. That is, we must find a way to show leisure-driven outcomes not within the medical model but the social model.To this end, Murray [12] and Mobily [11] have suggested integrating the International Classification of Functioning, Disability and Health (ICF) into TR/RT documentation. The American Therapeutic Recreation Association (ATRA) [16] has also stated that "the concepts and terminology of the ICF are compatible with recreational therapy practice." Using ICF as an assessment tool, Mori [17] presented a case showing that TR/RT can appropriately identify a client's needs, not demands, and provide intervention as well as information to support a client's disability acceptance and to encourage leisure participation with existent functional physical abilities.

ICF includes codes that can be integrated into TR/RT, such as "activities and participation" [18]. The ICF codes, however, are ambiguous and overlapping [19]. Therefore, integrating ICF into TR/
RT documentation inevitably would involve selecting matching codes for TR/RT and constructing a more detailed evaluation scale for each code. Most notably, we are waiting for reformation of ICF to include subjective factors. Ueda [20] strongly emphasized that understanding subjective factors among people with disabilities is essential, with these subjective factors including self-value, meaning and purpose in life, relationships with familiar people (such as love and trust), a sense of belonging and feeling of alienation in society, and basic attitudes toward life. These factors certainly have true significance in TR/RT. Paul Haun [21] has noted that "the recreation worker is the only person whose professional involvement is exclusively in the area of expressive rather than instrumental interaction." Do we just sit and wait for society to adapt to TR/RT, or continue to take steps, even if they are small ones, to change society? Do you believe it is too late?

\section{Acknowledgement}

Special thanks to members of the TR study group, Hiroaki Chino, Hiroko Murray, Yoshifumi Tajima, and Miwako Mori for their advice and opinions on this paper.

\section{References}

1. The future of jobs (2013) The onrushing wave. The Economist.

2. American Therapeutic Recreation Association. What is RT/TR?

3. National Council for Therapeutic Recreation Certification. About Recreational Therapy.

4. National Council for Therapeutic Recreation Certification. 2014 CTRS Job Analysis Report.

5. Occupational Outlook Handbook. U.S. Bureau of Labor Statistics.

6. Harkins L, Bedini LA (2013) Perceptions of healthcare administrators regarding recreation therapy in North Carolina. Annual in Therapeutic Recreation 21: 16-31.

7. Dieser RB (2015) Global Therapeutic Recreation: Should the American Therapeutic Recreation Profession and the American National Council for Therapeutic Recreation Certification (NCTRC) be replicated in Other Nations?World Leisure J 57: 2-5.

8. Mobily KE, Walter KB, Finley SE (2015) Deconstruction of TR/RT: does TR/RT contribute to the negative construction of disability? Part I. World Leisure J 57: 46-56.

9. Habblethwaite $S(2015)$ The professionalization of therapeutic recreation in Quebec, Canada. World Leisure J 57: 19-24.

10. Young MEM (2015) Therapeutic recreation as a developing profession in South Africa. World Leisure J 57: 34-45.

11. Mobily KE (2015) Should US recreation therapy be replicated globally? An opportunity to do better. Part II. World Leisure J 57: 57-68.

12. Murray H (2012) Koureishagatanoshisawokeikensurutame no therapeutic recreation enjyoriron model kenkyu: Leisure Ability Model nimotoduitaenjyoriron model no kpuchiku to jissennouyou. Unpublished doctoral dissertation.

13. Tsutsui $T$ (2012) Challenges and opportunities in the development of the community-based integrated care system in Japan: Significance of social capital with in community-based integrated care system. J Natl Inst Public Health 61: 96-103.

14. Luchauer B, Shurtleff T (2015) Meaningful components of exercise and active recreation for spinal cord injuries. OTJR: Occupation, Participation and Health 35: 232-238.

15. Richter KJ, Kaschalk SM (1996) The future of therapeutic recreation An existential outcome. In Sylvester C. Ed. Philosophy of Therapeutic Recreation: Ideas and issues vol. II. National Recreation and Park Association 86-91.

16. American Therapeutic Recreation Association. ATRA positon statement on the ICF.

17. Mori M (2015) Kaifukuki rehabilitation niokeru therapeutic recreation no kanousei: single study case niyorukentou. J Leisure Recreat Stud 77: 100103. 
Citation: Yoshioka (2016) Can recreation Exist in Healthcare? Recreational Therapy and Its Professionalization. Int J Phys Ther Rehab 2: 110. doi: http://dx.doi. org/10.15344/2455-7498/2016/110

Page 3 of 3

18. World Health Organization. International Classification of Functioning, Disability and Health.

19. Jelsma $J(2009)$ Use of the international classification of functioning, disability and health: A literature survey. J Rehabil Med 41: 1-12.

20. Ueda S (2015) ICF no tikai to katuyou. Houbunsha, Tokyo, Japan.

21. Haun P (1987) The wisdom of Paul Haun. In Sylvester C. Ed. Philosophy of Therapeutic Recreation: Ideas and issues vol. I. National Recreation and Park Association, Ashburn, VA 90-98. 